\title{
Strain path and microstructure evolution during severe deformation processing of an as-cast hypoeutectic Al-Si alloy
}

\author{
J. M. García-Infanta $\cdot$ A. P. Zhilyaev $\cdot$ F. Carreño $\cdot$ \\ O. A. Ruano $\cdot$ J. Q. Su $\cdot$ S. K. Menon $\cdot$ T. R. McNelley
}

Received: 5 March 2010/Accepted: 13 April 2010/Published online: 1 May 2010

(C) The Author(s) 2010. This article is published with open access at Springerlink.com

\begin{abstract}
Microstructure evolution in an as-cast $\mathrm{Na}$ modified $\mathrm{Al}-7 \% \mathrm{Si}$ (wt. pct.) alloy was examined during redundant and monotonic straining by repetitive equichannel angular pressing (ECAP) under ambient temperature conditions, and during friction stir processing (FSP). Redundant straining during repetitive ECAP was accomplished by processing following route $\mathrm{B}_{\mathrm{C}}$ while monotonic straining employed route A. Single- and multi-pass FSP was conducted on this same as-cast material using an FSP tool having a threaded pin. The as-cast microstructure comprises equiaxed primary $\alpha$ dendrite cells embedded in the Al-Si eutectic constituent. The evolution of this microstructure during repetitive ECAP can be described by idealized models of this process. The primary and eutectic constituents can still be discerned and the Si particle distribution is not homogenized even during ambient temperature processing involving von Mises strains $>9$.0. In contrast, the primary and eutectic constituents cannot be distinguished in the stir zone after even a single FSP pass. Strain estimates based on the shape change of the primary $\alpha$ constituent indicate that the $\mathrm{Si}$ particle distribution has become homogeneous at local von Mises strains of 2.5-3.0
\end{abstract}

J. M. García-Infanta · A. P. Zhilyaev · F. Carreño · O. A. Ruano Department of Physical Metallurgy, Centro Nacional de Investigaciones Metalúrgicas (CENIM), CSIC, Av. de Gregorio del Amo 8, 28040 Madrid, Spain

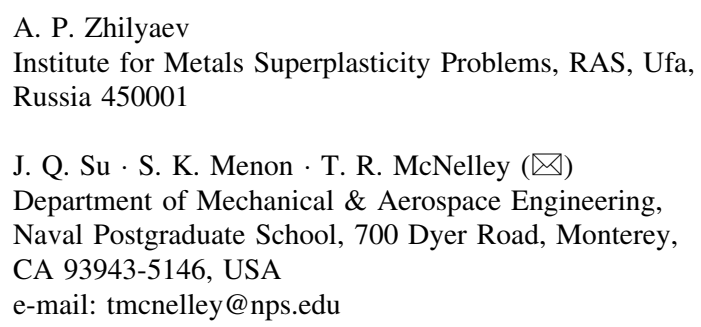

during the FSP thermomechanical cycle. Mechanical property data are consistent with strain path during SPD processing by repetitive ECAP and FSP.

\section{Introduction}

Severe deformation processing (SPD) methods such as repetitive equi-channel angular pressing (ECAP) $[1,2]$ and high-pressure torsion (HPT) $[3,4]$ are typically conducted at ambient temperature in order to produce highly refined and even nanostructured bulk materials. These methods have been applied most widely to pure metals and singlephase solid solution alloys wherein the undeformed grain structure is replaced initially by a deformation-induced substructure that gives way to equiaxed, highly refined grains at large SPD strains. At large strains the prior grain structure can no longer be distinguished.

Recent investigations into SPD of multi-constituent alloys have included the examination microstructure evolution in as-cast $\mathrm{Al}-7 \% \mathrm{Si}$ (wt. pct.) by repetitive ECAP [5-7]. The as-cast microstructure in this alloy comprises primary and eutectic constituents in a dendritic solidification microstructure. The primary constituent is the $\alpha$-phase terminal solid solution in the Al-Si binary system, and the primary $\alpha$ cells are approximately spheroidal in shape. A $0.02 \% \mathrm{Na}$ addition results in a refined eutectic constituent that contains mainly irregular $\mathrm{Si}$ particles although there is a small fraction of $\mathrm{Al}_{5} \mathrm{FeSi}$ needle-like particles. In this recent work, the eutectic constituent in alloy provided a marker that delineated the shape change in the microstructure during repetitive ECAP [5-7].

The ECAP process has been described in detail elsewhere $[1,2,8-10]$. Briefly, a billet is pressed through a die having two channels of equal inlet and outlet areas and 
with the channels inclined at an angle. The channel axes intersect at a point within the die, and, so, the billet experiences shear deformation as it passes through the plane defined by the intersection of the die channels. The billet strain depends on the angle between the channel axes, the radius of curvature at the inner and outer corners of the die channel intersection, and the friction conditions that prevail between the die walls and the billet. Repetitive pressing operations may be conducted on a billet since its cross-sectional area does not change upon passing through the die and therefore large cumulative strains can be introduced. The simple shear strain per ECAP pass is $\gamma_{\mathrm{p}}=2 \cot (\varphi / 2)$, where $\varphi$ is the angle of inclination between the channel axes. Then, the total cumulative strain $\gamma_{\mathrm{T}}=N\left|\gamma_{\mathrm{p}}\right|$, where $N$ is the number of ECAP passes. The ECAP strain path can be controlled by billet rotation between successive passes. In following route $A$ the billet is not rotated between successive passes and the strain increases monotonically with $N$. During pressing by route $\mathrm{B}_{\mathrm{C}}$, rotation of the billet by $90^{\circ}$ on successive passes results in redundant strains every $4 N$ passes.

The primary dendrite cells became increasingly elongated along the direction of maximum principal strain in the flow plane of material processed by route A during successive passes following this route. In the plane transverse to the billet and die exit channel axis the primary dendrite cells became compressed along the direction parallel to the axis of the die entrance channel. From an idealized model of deformation by route $\mathrm{A}$ there is no distortion on the top plane of the billet, i.e., the billet plane perpendicular to the axis of the die entrance channel, and no distortion of the primary dendrite cells or the eutectic constituent was observed. Microscopy examination of material processed through either four or eight passes by route $\mathrm{B}_{\mathrm{C}}$ showed that there was essentially no distortion of the primary dendrite cell structure and the eutectic constituent on any of three orthogonal planes in the as-pressed billets and this observation is, again, consistent with idealized model of ECAP deformation by this route. While highly refined grains were observed within the primary $\alpha$ constituent, the Si particles remained within the eutectic constituent and were not redistributed into the primary despite a cumulative shear strain 16 (corresponding to a von Mises equivalent strain >9.0). Altogether, these observations suggest that non-deforming particles are not being redistributed during SPD at ambient temperature [5-7].

Friction stir processing (FSP) is an allied technology of friction stir welding (FSW), a solid-state joining method developed at The Welding Institute [11]. There is an extensive literature on these technologies [e.g., 12, 13]. Briefly, a rotating non-consumable cylindrical tool with a concentric projecting pin is pressed into a work piece surface. A combination of frictional and adiabatic heating allows the pin to penetrate as the work piece softens. Once the cylindrical shoulder of the tool has come into contact with the work piece surface the tool may be traversed across the surface to process a volume of material (referred to as the stir zone) defined by the tool pin profile and the traversing pattern. The frictional and adiabatic heating leads to formation of a plasticized column of material surrounding the tool pin and underneath the tool shoulder, and the straining in this column is dominated by shear. The resulting FSP thermomechanical cycle involves rapid heating to a peak temperature $0.7 T_{\text {Melt }} \leq T_{\text {Peak }} \leq 0.95 T_{\text {Melt }}$, a brief dwell (typically $1-5 \mathrm{~s}$ ) above $0.9 T_{\text {Peak }}$ and slower cooling back to the initial work piece temperature [14]. Modeling [15, 16] of FSW/P has shown that straining is monotonic in nature and that the von Mises equivalent strains in the stir zone are typically $\geq 10$, i.e., larger than the equivalent strains typically encountered after eight passes through a $90^{\circ}$ ECAP die. In this paper, the evolution of microstructure from locations in the unprocessed, as-cast material into the stir zone is evaluated following FSP of this Na modified Al-7Si alloy. Comparison is made to the microstructures and mechanical properties of this same material after repetitive ECAP through eight passes by routes $\mathrm{A}$ and $\mathrm{B}_{\mathrm{C}}$.

\section{Experimental procedures}

Details of the alloy preparation and ECAP processing have been given previously [5-7]. Briefly, 99.99\% $\mathrm{Al}$ and an $\mathrm{Al}-12.3 \% \mathrm{Si}$ master alloy were melted in the required proportions, and a nominal $0.02 \% \mathrm{Na}$ addition was also made in order to modify the Si particle morphology and to refine Si particle size in the eutectic constituent. The alloy was poured into a $400 \times 250 \times 40 \mathrm{~mm}$ mold and spectrographic analysis revealed that the resulting ingot composition was $\mathrm{Al}-7.0 \% \mathrm{Si}-0.3 \% \mathrm{Fe}$. Billets $90 \times 10 \times$ $10 \mathrm{~mm}$ in size were machined from the as-cast ingot and were pressed at $10 \mathrm{~mm} \mathrm{~min}^{-1}$ through a sharp-cornered $90^{\circ}$ ECAP die having channels $10 \times 10 \mathrm{~mm}$ in crosssection. A schematic of the ECAP die using in this study is shown in Fig. 1a. In this diagram, FP, TP, and CP refer to the flow plane, the top plane and the cross-section plane of a billet after passing through the die. The samples of interest in the current work were processed either by route $A$ or by route $B_{C}$.

Billets for FSP were machined to an approximate size of $50 \times 150 \times 6 \mathrm{~mm}$ from the same as-cast ingot. The tool was fabricated in H-13 steel and hardened to HRC52. The tool shoulder diameter was $18 \mathrm{~mm}$ and the shoulder included a $3^{\circ}$ cone angle. The pin was a truncated cone in shape having a $6 \mathrm{~mm}$ base diameter, a $4 \mathrm{~mm}$ tip diameter 
(a)

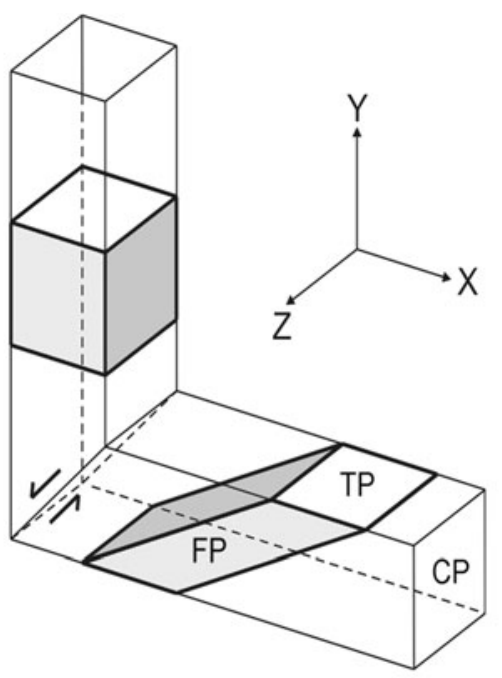

(b)

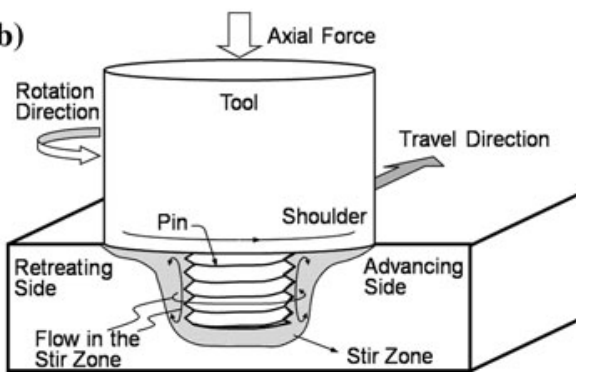

Fig. 1 A schematic illustration of an ECAP pass is shown in a and shows a simple shear as a cubical volume element passes through the die channel intersection. $F P, T P$, and $C P$ denote the flow plane, top plane, and cross-section plane after pressing. An FSP traverse is illustrated in $\mathbf{b}$. On the advancing side the tool rotation and translation are parallel while on the retreating side they are antiparallel

and was $5 \mathrm{~mm}$ in length. The pin was also threaded. FSP was conducted in a milling machine with tool rotation rates of either 800 or $2000 \mathrm{rpm}$, and with the tool tilted $3^{\circ}$ away from the direction of tool advance. A schematic illustrating FSP and indicating some of the process terminology is shown in Fig. 1b. Multi-pass processing was accomplished by parallel traverses successively offset by $2.5 \mathrm{~mm}$.

Conventional methods of metallographic sample preparation were employed. The final mechanical polishing stage employed a $0.05 \mu \mathrm{m}$ colloidal silica suspension. This was followed by electropolishing in a solution of $20 \%$ $\mathrm{HNO}_{3}+80 \% \quad \mathrm{CH}_{3} \mathrm{OH}$ (by volume) at $20 \mathrm{~V}$ for $3 \mathrm{~s}$. Samples were examined in a using both secondary and backscatter electron (BSE) imaging conditions in a Zeiss Neon 40 FE-SEM operating at $30 \mathrm{kV}$.

\section{Results}

The as-cast microstructure is shown in the secondary electron (SE) images in Fig. 2. The primary $\alpha$ dendrite cells vary from 25 to $65 \mu \mathrm{m}$ in size while the eutectic constituent
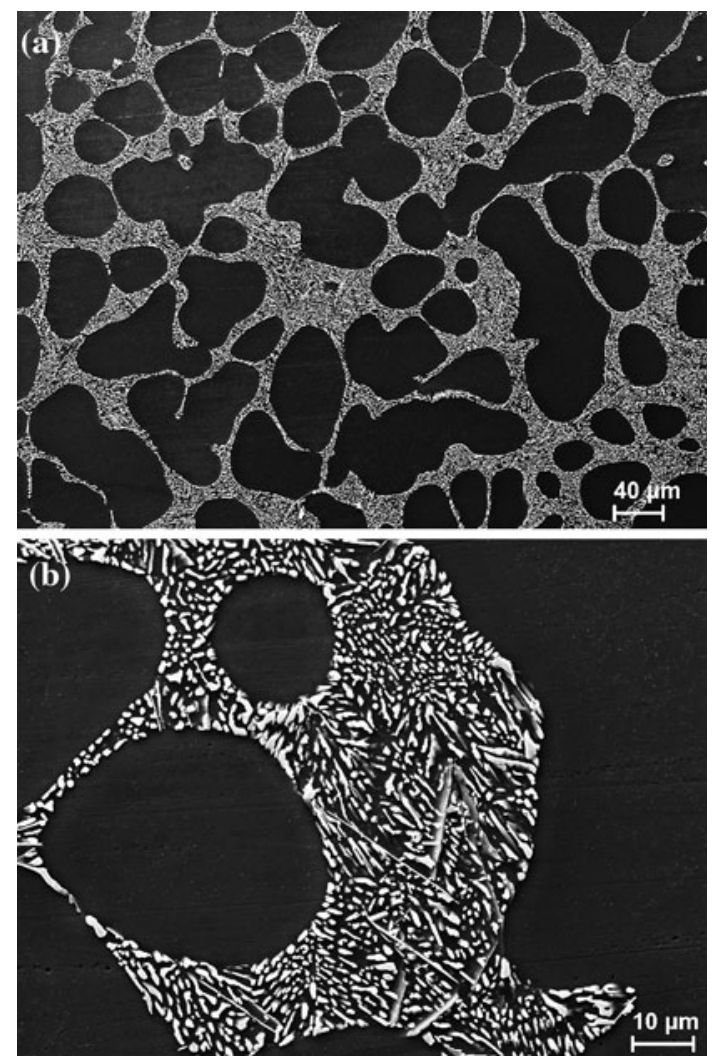

Fig. 2 Secondary electron (SE) image in a of the as-cast $\mathrm{Al}-7 \% \mathrm{Si}$ alloy showing the primary $\alpha$ and eutectic constituents. The SE image in b shows the eutectic at higher resolution

includes irregularly shaped Si particles $0.5-2.0 \mu \mathrm{m}$ in size and needle-like $\mathrm{Al}_{5} \mathrm{FeSi}$ particles up to $10 \mu \mathrm{m}$ in length. The path-dependence of microstructure evolution during repetitive ECAP is illustrated in Fig. 3. These SE images are all from the flow plane of the last pass in the pressing sequence. Results for redundant straining by route $\mathrm{B}_{\mathrm{C}}$ are shown in Fig. 3a and b after four or eight passes, respectively. In both cases the primary $\alpha$ and eutectic constituents are still easily discerned; the primary $\alpha$ cells are similar in size to those in the as-cast material (note the difference in magnification in comparing Fig. 3a, b). The Si particles in the eutectic appear essentially unaffected by the deformation while the needle-like $\mathrm{Al}_{5} \mathrm{FeSi}$ particles are no longer apparent. In contrast, the images in Fig. $3 \mathrm{c}$ and d show that the primary $\alpha$ and eutectic constituents become elongated in the direction of the maximum principal strain during monotonic ECAP deformation following route A. After four passes (Fig. 3c) the principal strain direction is expected to be inclined by $7.1^{\circ}$ and, after eight passes, by $3.6^{\circ}$ to the billet axis. Measured inclination angles were reported previously as $7.2^{\circ} \pm 0.5^{\circ}$ and $3.5^{\circ} \pm 0.3^{\circ}$ from optical microscopy analysis [6]. Altogether, the data of Fig. 3 support the conclusions of previous work in that the distortions of the primary and eutectic constituents are 
Fig. 3 SE images show the FP microstructure for route $B_{C}$ after four passes in $\mathbf{a}$ and eight passes in $\mathbf{b}$; and the FP microstructure for route $\mathrm{A}$ is shown after four passes in $\mathbf{c}$ and eight passes in $\mathbf{d}$
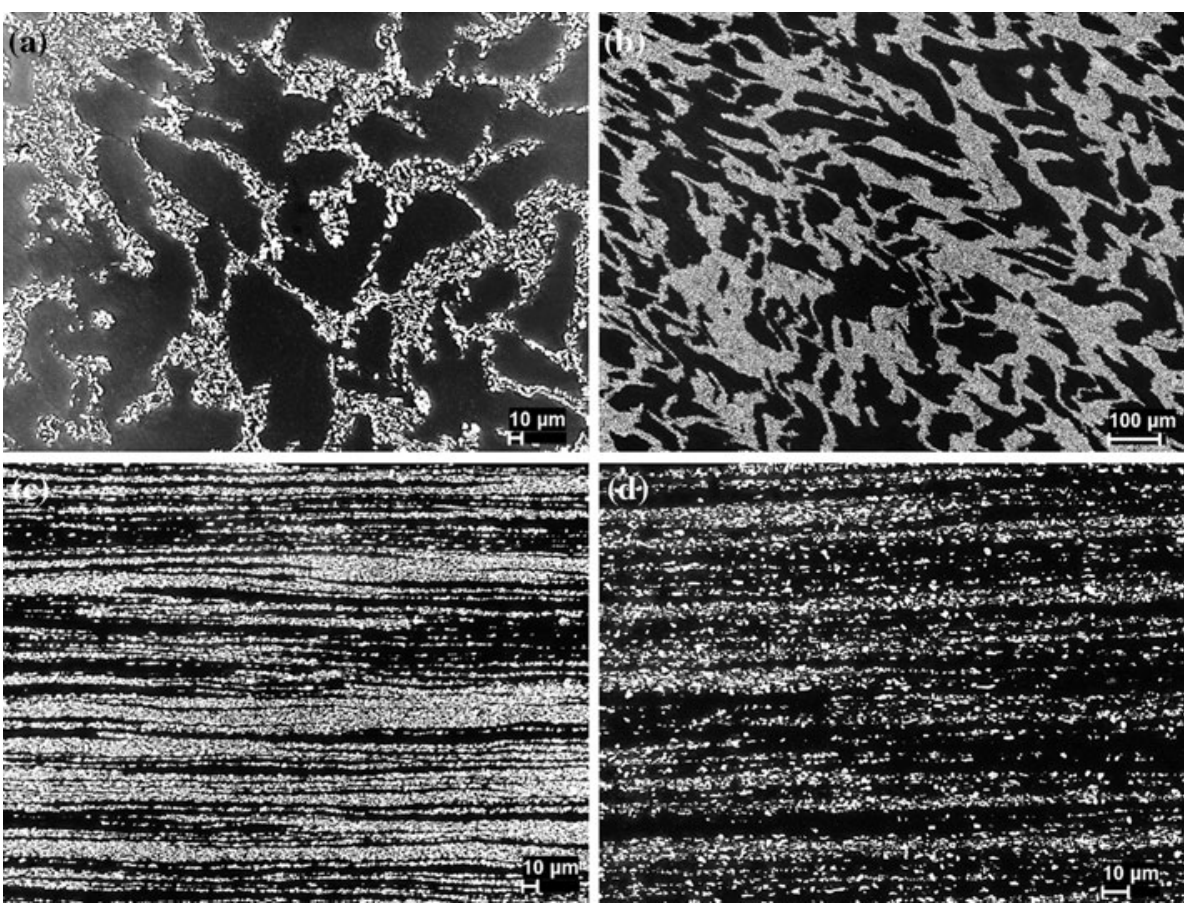

congruent with the distortions of idealized ECAP, and these constituents remain distinct even at large redundant strains [6]. This also suggests that the distribution of nondeforming particles is not homogenized by SPD involving shear at ambient temperatures.

The advancing side of the stir zone for the outside of final FSP pass is shown in Fig. 4a for material processed at $800 \mathrm{rpm}$. This SE image was obtained from the plane transverse to the axis of tool advance in the sample and shows that the primary and eutectic constituents are undistorted in the base material at the lower right-hand side of the field of view. In a region between the base metal and stir zone the primary and eutectic constituents have become distorted due to deformation induced by the tool. This region is often referred to as the thermomechanically affected zone (TMAZ). The stir zone is the large area to the upper left in this image and neither the primary nor the eutectic can be discerned in this region of the image. The interface between the TMAZ and stir zone is shown at higher resolution in Fig. 4b. The distortion of the primary and eutectic constituents is apparent at this location. The distortion appears to increase as the stir zone is approached and also appears to be monotonic in nature as suggested by comparison of Fig. $4 b$ to Fig. $3 c$ and d.

The BSE image in Fig. $4 \mathrm{c}$ is also from the TMAZ. This imaging condition reveals the Al grain boundaries and shows the onset of recrystallization in the primary $\alpha$. The BSE image in Fig. 4d shows a representative microstructure from within the stir zone. This microstructure comprises a uniform distribution of $\mathrm{Si}$ particles in a matrix of recrystallized $\mathrm{Al}$ grains $4.7 \mu \mathrm{m}$ in size. This grain size likely reflects particle stimulated nucleation of recrystallization [17] during the FSP thermomechanical cycle. The Si particles are similar in size and morphology to those in the eutectic constituent in the as-cast condition (Fig. 2) although, again, the needle-like $\mathrm{Al}_{5} \mathrm{FeSi}$ are no longer present. The primary $\alpha$ and Al-Si eutectic constituents are no longer apparent, and this suggests that the nondeforming $\mathrm{Si}$ particles have been also been redistributed from the eutectic constituent into the primary $\alpha$ during FSP.

The magnitude of the strain associated with the processes of particle redistribution and microstructure homogenization was estimated by evaluating the distortion of the primary $\alpha$ at points along a traversing line from the as-cast base metal across the TMAZ and into the stir zone. The line of traverse was perpendicular to the TMAZ-stir zone interface (as illustrated by the schematic line in Fig. 4b). The primary $\alpha$ cells were treated as initially circular in the base metal and as ellipsoids in the TMAZ, as suggest by the insets in Fig. 5. At each location along the line the minor axis dimensions of approximately 25 primary $\alpha$ cells were averaged and the local strain was estimated from the relationship $\varepsilon=-\ln \left(a / a_{0}\right)$, where $a$ is the average minor axis dimension at each location and $a_{0}$ is the average diameter of the cells in the base material. The results of this procedure are plotted in Fig. 5 as the local strain, $-\ln \left(a / a_{0}\right)$, as a function of distance along the traversing line from the stir zone-TMAZ interface toward base metal. These data indicate that the TMAZ extends approximately $600 \mu \mathrm{m}$ from base metal to the stir zone at the location of this traverse. Also, the strain increases from 0 in base metal to approximately 2.7 at the stir zone-TMAZ interface before 
Fig. 4 The SE image in a shows the advancing side of the stir zone, the TMAZ and base metal while the SE image in b shows the interface between the TMAZ and the stir zone. The dotted line is a schematic representation of the location of strain estimates. The BSE image in $\mathbf{c}$ shows that recrystallization occurs in the TMAZ while particle redistribution results in a homogeneous and refined structure in the stir zone in $\mathbf{d}$
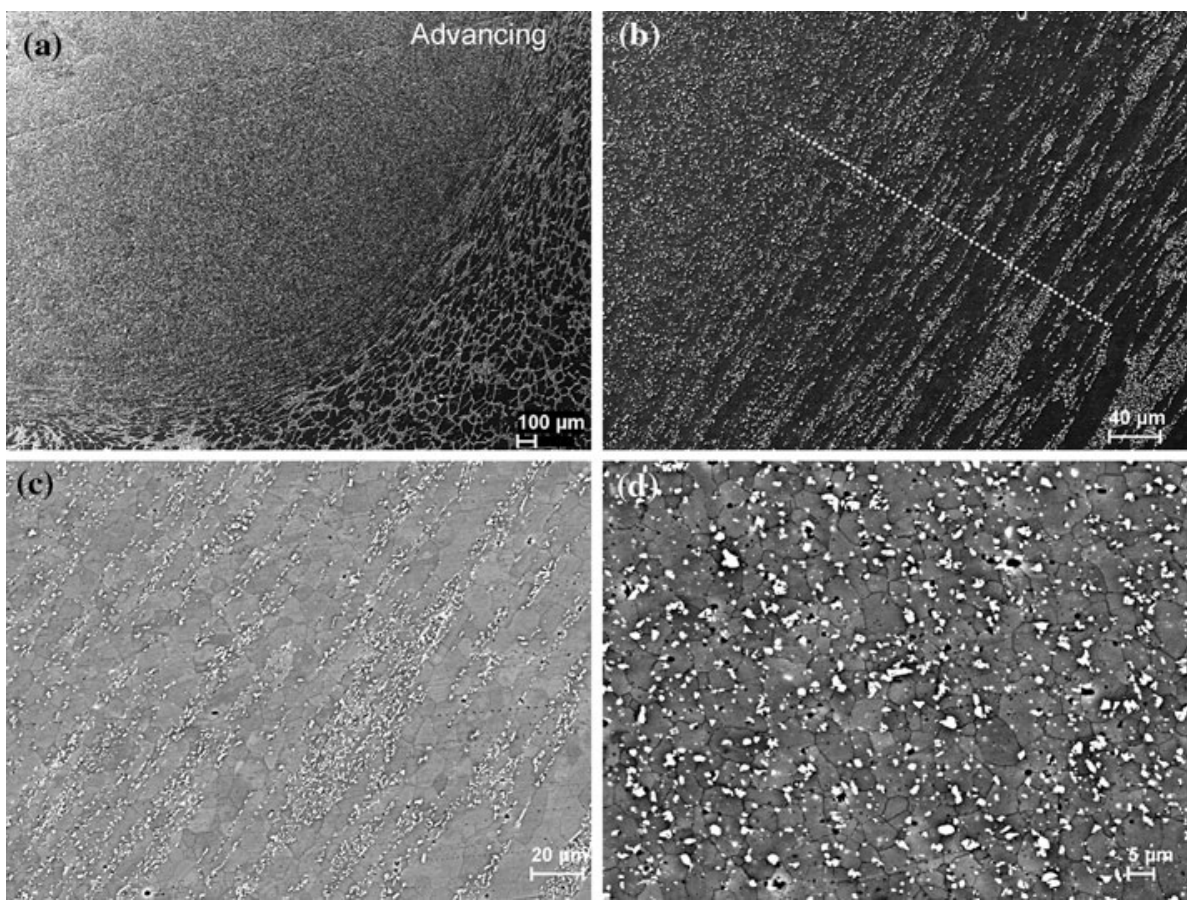

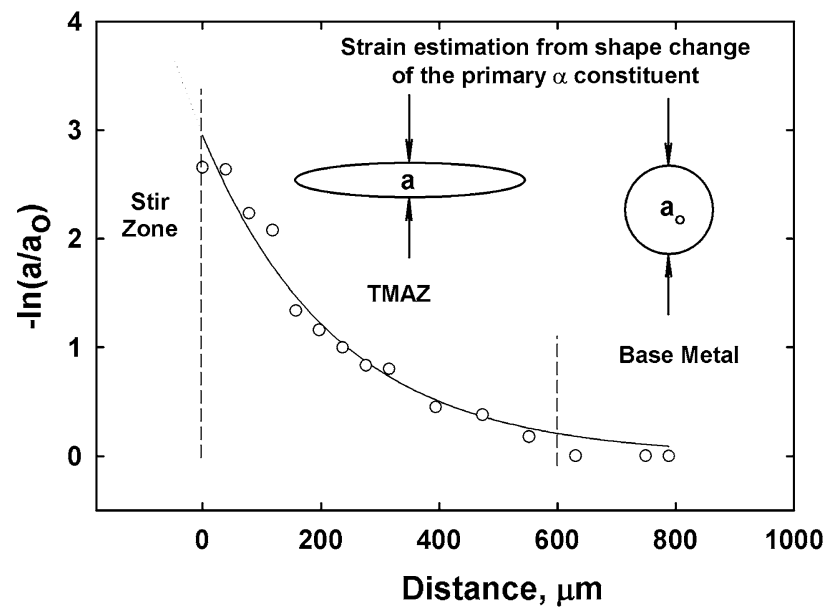

Fig. 5 A plot of the local strain as determined by the shape change of the primary $\alpha$ from base metal through the TMAZ and into the stir zone

the particle distribution has become homogeneous and the primary $\alpha$ can no longer be discerned onward into the stir zone.

The grain sizes in the primary $\alpha$ constituent of materials processed by ECAP through eight passes following routes $\mathrm{B}_{\mathrm{C}}$ and $\mathrm{A}$ are shown by the BSE images in Fig. 6a and b, respectively. The channeling contrast in these FE-SEM images suggests that SPD results in a (sub)grain size of approximately $300 \mathrm{~nm}$ after eight passes. In prior work [6], it was shown that these fine grains evolve by processes of dislocation reaction and grain subdivision in the primary $\alpha$. Also, it has been shown that these fine grains are stabilized by fine Si precipitation on their boundaries [7]. Indeed, precipitation of fine Si particles $10-50 \mathrm{~nm}$ in size is shown in the SE images in Fig. 6c and d for materials processed by routes $B_{C}$ and $A$, respectively. The refined size of these $\mathrm{Si}$ particles is consistent with the development of $\mathrm{Si}$ supersaturation in the primary $\alpha$ during cooling after pouring to produce the as-cast condition, and their formation on the (sub)grain boundaries within the primary $\alpha$ suggests that precipitation took place concurrently with or immediately after conclusion of the ECAP processing route [7].

Stress-strain testing was conducted on miniature tensile samples prepared from the as-cast material, from routes A and $\mathrm{B}_{\mathrm{C}}$ materials after eight ECAP passes, and from the stir zones of materials processed at either 800 or $2000 \mathrm{rpm}$. The tensile axes of samples from ECAP'ed material were parallel to the billet axes of the as-pressed billets while the tensile axes of the samples from FSP'ed materials were parallel to the tool traversing direction. Results of these tests are summarized in Fig. 7. The as-cast condition exhibits the lowest yield strength, $\approx 85 \mathrm{MPa}$, among these tests and a tensile ductility of $15 \%$ elongation to fracture. The ECAP'ed materials have been strengthened by the processing and these data indicate that the yield strength is $\approx 215 \mathrm{MPa}$ for both route $\mathrm{A}$ and route $\mathrm{B}_{\mathrm{C}}$ materials. The increase in yield strength due to ECAP is accompanied by a low subsequent rate of strain hardening, with the onset of plastic instability and necking at elongations of either 8 or $12 \%$ in route $\mathrm{B}_{\mathrm{C}}$ or $\mathrm{A}$ materials, respectively. It is noteworthy that the elongation to fracture of material processed by route $\mathrm{B}_{\mathrm{C}}$ is less than half that of material processed by 
Fig. 6 BSE images from the primary $\alpha$ are shown in a for ECAP Al-7\%Si material processed eight passes by route $\mathrm{B}_{\mathrm{C}}$ and in $\mathbf{b}$ for this material processed eight passes by route A. Highly refined (sub)grains $\approx 300 \mathrm{~nm}$ in size are apparent in these FE-SEM highresolution images. Ultrafine grains are stabilized by fine $\mathrm{Si}$ precipitation; this is best shown in the SE images for eight passes by route $B_{C}$ in $\mathbf{c}$ and for eight passes by route $\mathrm{A}$ in $\mathbf{d}$
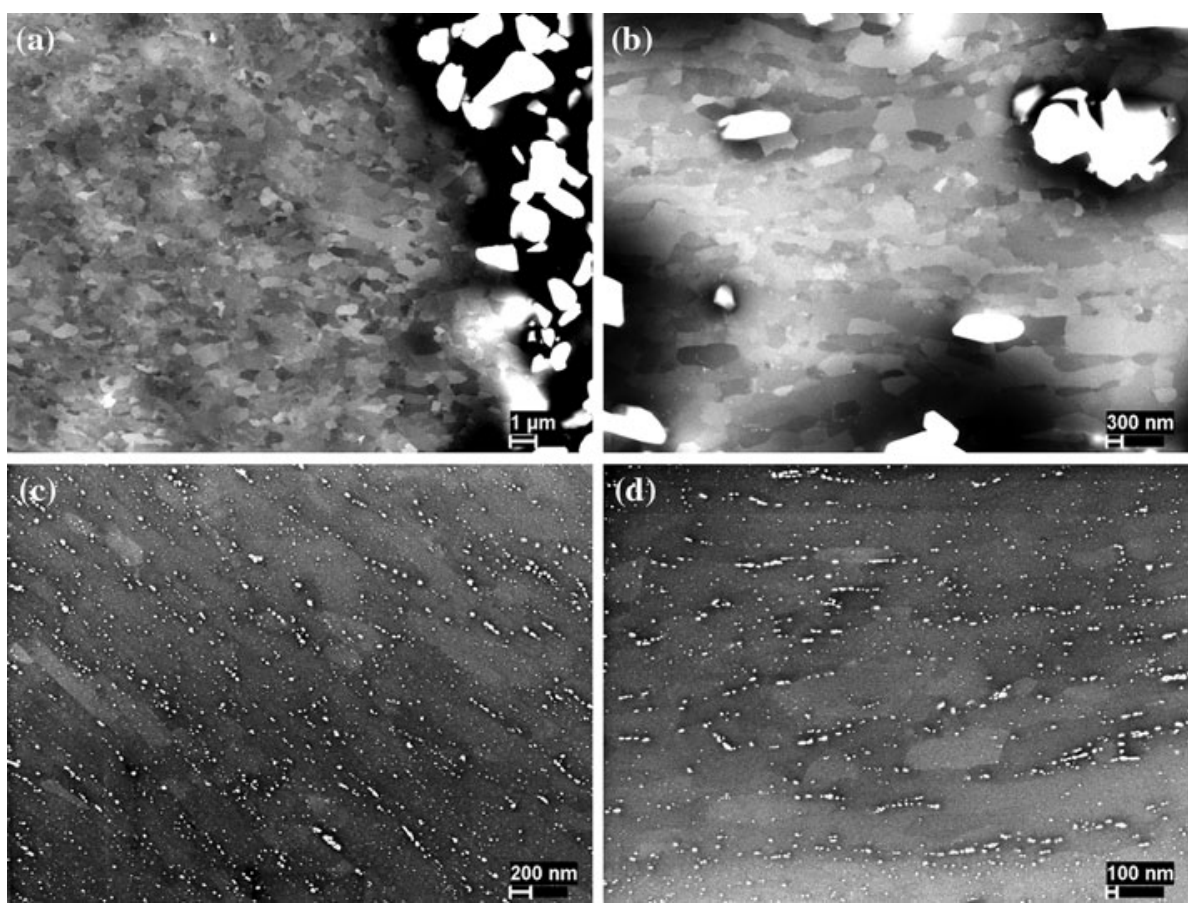

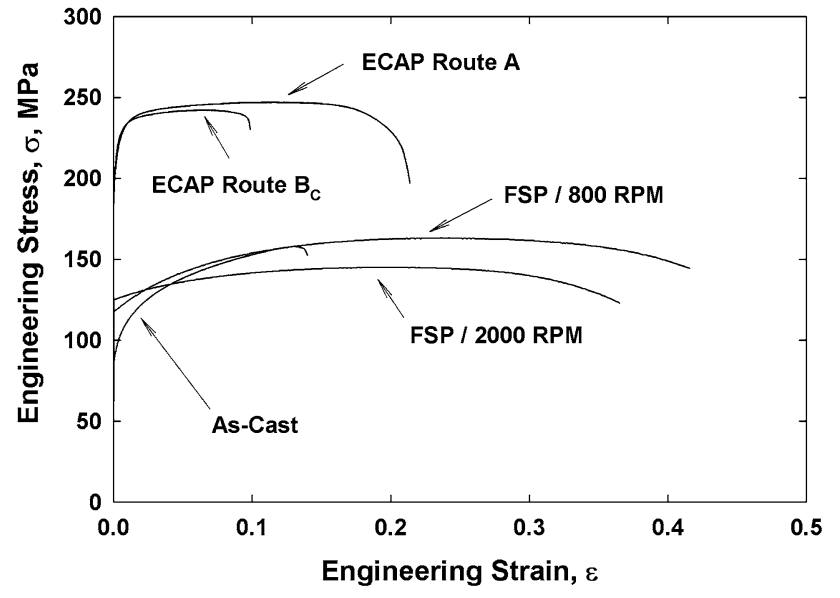

Fig. 7 Plots of stress as a function of strain for as-cast $\mathrm{Al}-7 \% \mathrm{Si}$ material, this same material after ECAP at ambient temperatures for eight passes by routes $A$ and $B_{C}$, and for samples from the stir zone of this material after FSP at 800 and $2000 \mathrm{rpm}$

route A. In a previous report this was attributed to the presence in the microstructure of a continuous eutectic constituent that facilitated strain localization within this constituent and, thus, reduced ductility [5, 18]. In contrast, the elongated, fibrous structure produced by route A contributed to higher ductility when tension testing is conducted in a direction parallel to the billet (and, approximately, the fiber) axis.

The stir zone grain size of $4.7 \mu \mathrm{m}$ that was developed during FSP is consistent with the yield strength values for the FSP'ed materials that are intermediate $(\approx 120$ $125 \mathrm{MPa})$ to those for the as-cast and ECAP'ed materials.
The primary $\alpha$ cells are $25-65 \mu \mathrm{m}$ in size in the as-cast material. These data suggest, at most, a weak dependence of the stress-strain curve on rpm during processing, although the higher tensile strength observed for the material processed at $800 \mathrm{rpm}$ may be consistent with lower stir zone peak temperatures. The tensile ductility values for as-cast material of $15 \%$ elongation to failure when compared to values of $38-42 \%$ for the FSP'ed samples suggest that microstructure homogeneity is again a factor in ductility. Indeed, the eutectic constituent in the as-cast material was a preferred crack path and facilitated strain localization [5-7, 18]. Both the as-cast and the FSP'ed materials exhibit greater rates of strain hardening after yield when compared to materials processed by ECAP. This is reflected in the delay of plastic instability and necking to elongations $>20 \%$ in the FSP'ed materials.

\section{Discussion}

The microstructure of this as-cast $\mathrm{Al}-7 \% \mathrm{Si}$ alloy exhibits a dendritic structure comprising approximately spheroidal primary $\alpha$ cells embedded in an $\mathrm{Al}-\mathrm{Si}$ eutectic. During repetitive ECAP at ambient temperature these constituents exhibit shape changes that are congruent with the shape change of a volume element in an idealized model of this process. Thus, ECAP of as-cast alloy by route $\mathrm{B}_{\mathrm{C}}$ involves redundant strains every four passes and approximately restores the primary and eutectic constituents to their original shapes after four or eight passes. Grain subdivision results in the introduction of highly refined (sub)grains 
$300 \mathrm{~nm}$ in size within the primary $\alpha$ but the Si particles in the eutectic are not redistributed even after eight passes (a cumulative von Mises strain $\approx 9.2$ ) and the microstructure remains inhomogeneous. This is reflected in reduced tensile ductility because the continuous eutectic constituent facilitates strain localization. ECAP following route A involves monotonic straining and results in elongated primary $\alpha$ and fiber-like distributions of the Si particles in the eutectic. The fiber axis coincides with the direction of maximum principal strain on successive passes following route $\mathrm{A}$. Nevertheless, the $\mathrm{Si}$ particles do not become homogeneously distributed although the tensile ductility is higher along the billet axis (and near the fiber axis in the microstructure) in comparison to the ductility of material processed by the redundant strain path of route $B_{C}$.

The thermomechanical cycle of FSP apparently is dominated by monotonic shearing but nevertheless results in homogenization of the distribution of the non-deforming Si particles as the von Mises strain attains a value of $\approx 3.0$ at the TMAZ-stir zone interface. The homogenization of the $\mathrm{Si}$ particle distribution is accompanied by particle stimulated nucleation of recrystallization [17] leading to a grain size of $4.7 \mu \mathrm{m}$ in the stir zone. This is coarser than the grain size attained by monotonic $\operatorname{ECAP}(\approx 300 \mathrm{~nm})$, and reflects the heating associated with the FSP thermomechanical cycle wherein peak temperatures are expected to be $\geq 0.7 T_{\text {Melt }}$.

The mechanism of particle redistribution during SPD remains to be determined. In order to accomplish homogenization of microstructures involving inhomogeneous distributions of non-deforming particles embedded in a deformable matrix the particles must experience displacements that do not coincide with the displacement field expected from the externally imposed strain. The lack of redistribution and homogenization during ambient temperature ECAP following either routes $A$ or $B_{C}$ while redistribution and homogenization appears to occur readily during the thermomechanical cycle of FSP suggests that temperature, and thus diffusion, is an important factor. Diffusive processes might include bulk diffusion in the surrounding matrix as well as interface diffusion in the particle-matrix interface. Also, the absence of damage in the form of particle cracking and cavity formation in the matrix suggests that stress state, and especially the hydrostatic component of the stress state, may also be a factor.

Strengthening due to ECAP processing of this material apparently reflects contributions from strain hardening, grain refinement, solid solution effects and dispersion strengthening. The presence of a refined (sub)grain structure reflects the severe plastic deformation at ambient temperature associated with repetitive ECAP. The presence of $\mathrm{Si}$ in solution and a fine $\mathrm{Si}$ precipitate particle dispersion within the primary $\alpha$ are also contributing factors in strengthening of the ECAP'ed materials. In contrast, the increased temperature associated with FSP thermomechanical cycle has resulted in moderate grain refinement from the as-cast condition and the strength of the FSP materials evidently reflects mainly the moderate grain refinement and solid solution effects in the absence of strain hardening and dispersion effects.

Finally, two factors are important in the ductility of these materials. The first is the presence of the eutectic constituent in as-cast material and the restoration of this constituent during repetitive ECAP following the redundant route $B_{C}$. This evidently facilitates strain localization within this constituent and results in reduced ductility. In contrast, the fibrous $\mathrm{Si}$ particle distribution in route $\mathrm{A}$ material and the fully homogeneous particle distribution in material processed by FSP evidently retard strain localization and lead to higher ductility. The second factor is the rate of strain hardening during plastic deformation after yielding. Increased rates of hardening retard the onset of plastic instability and necking, thereby enhancing ductility, and this accounts for the enhanced ductility in material processed by FSP. In contrast, severe deformation during ECAP has resulted in the exhaustion of further capacity to strain harden and thereby contributed to reduced ductility.

\section{Conclusions}

The following conclusions may be drawn from this investigation.

1. Microstructure evolution during repetitive ECAP at ambient temperature of the as-cast $\mathrm{Al}-7 \% \mathrm{Si}$ alloy is congruent with the strain path. Monotonic straining by route $A$ results in elongation in the flow plane of the primary $\alpha$ and the Al-Si eutectic along the axis of maximum principal strain and the formation of a fibrous distribution of the $\mathrm{Si}$ particles. Redundant straining by route $B_{C}$ results in restoration of the primary $\alpha$-eutectic structure every four passes and does not homogenize the particle distribution even for cumulative von Mises strains as large as 9.2.

2. During FSP, monotonic straining in shear results in homogenization of the Si particle distribution within an apparent von Mises strain of 3.0. This reflects contributions of diffusive processes during the brief thermomechanical cycle associated with the process.

3. Grain refinement in the Al matrix as well as strain hardening, dispersion strengthening and solid solution effects contribute to strengthening by ECAP. Ductility in material processed by the redundant strain path of route $B_{C}$ is reduced by the presence of a continuous 
eutectic component in the microstructure and strain localization. Also, reduced ductility values in materials processed by ECAP reflect low strains for the onset of necking associated with low rates of strain hardening after yielding. Ductility exceeding $40 \%$ elongation to fracture in stir zone material after FSP reflects the homogenization of microstructure by particle redistribution in the absence of damage to the particles or matrix as well as increased strains for the onset of necking due to increased rates of strain hardening.

Acknowledgements The authors acknowledge financial support from CICYT under program MAT2003/01172. J. G. I. would like to express his thanks to the Spanish Ministry of Education and Science for providing a FPI fellowship number BES-2004-4865, and travel expenses. J. Q. S., S. K. M., and T. R. M. acknowledge partial support for this work by the U.S. Air Force Office of Scientific Research under funding document no. F1ATA06058G001. J. Q. S. acknowledges a U.S. National Research Council Fellowship.

Open Access This article is distributed under the terms of the Creative Commons Attribution Noncommercial License which permits any noncommercial use, distribution, and reproduction in any medium, provided the original author(s) and source are credited.

\section{References}

1. Segal VM, Reznikov VI, Drobyshevskiy AE, Kopylov VI (1981) Russ Metall 1:99

2. Valiev RZ, Langdon TG (2006) Prog Mater Sci 51:881. doi: 10.1016/j.pmatersci.2006.02.003

3. Zhilyaev AP, Langdon TG (2008) Prog Mater Sci 53:893. doi: 10.1016/j.pmatsci.2008.03.002
4. Zhilyaev AP, Nurislamova GV, Kim B-K, Baró MD, Szpunar JA, Langdon TG (2003) Acta Mater 51:753. doi:10.1016/S13596454(02)00466-4

5. Swaminathan S, García-Infanta JM, McNelley TR, Ruano OA, Carreño F (2008) J Mater Sci 43:7501. doi:10.1007/s10853008-2625-y

6. García-Infanta JM, Swaminathan S, Zhilyaev AP, Carreño F, Ruano OA, McNelley TR (2008) Mater Sci Eng A A485:160. doi:10.1016/jmsea.2007.07.080

7. García-Infanta JM, Swaminathan S, Cepeda-Jiménez CM, McNelley TR, Ruano OA, Carreño F (2009) J Alloys Compd 478:139

8. Segal VM (2003) Mater Sci Eng A A345:36

9. Furukawa M, Iwahashi Y, Horita Z, Nemoto M, Langdon TG (1998) Mater Sci Eng A A257:328

10. Iwahashi Y, Horita Z, Nemoto M, Langdon TG (1998) Acta Mater 46:3317

11. Thomas WM, Nicholas ED, Needham JC, Murch MG, Templesmith P, Dawes CJ (1991) GB Patent 9125978.8

12. Mishra RS, Ma ZY (2005) Mater Sci Eng R 50:1

13. Mishra RS, Mahoney MW (eds) (2007) Friction stir welding and processing. ASM International, Materials Park, OH

14. Swaminathan S, Oh-Ishi K, Zhilyaev AP, Fuller CB, London B, Mahoney MW, McNelley TR (2010) Metall Mater Trans A. doi: 10.1007/s11661-009-0140-7

15. Askari AS, Silling S, London B, Mahoney MW (2001) In: Jata $\mathrm{KV}$ et al (eds) Friction stir welding and processing. TMS, Warrendale, PA, p 43

16. Shercliff HR, Colegrove PA (2007) Chapter 10. In: Mishra RS, Mahoney MW (eds) Friction stir welding and processing. ASM International, Materials Park, OH, p 187

17. Humphreys FJ, Hatherly M (2004) Recrystallization and related annealing phenomena. Elsevier, Oxford

18. García-Infanta JM, Zhilyaev AP, Cepeda-Jiménez CM, Ruano OA, Carreño F (2008) Scr Mater 58:138 